\title{
Morphological variation assessment in different accessions of Plectranthus forskohlii (Willd) Briq. from South India
}

\author{
Ganapathy Murugan Alagu Lakshmanan*, Selvarasuvasuki Manikandan \\ Department of Botany, Annamalai University, Annamalai Nagar 608 002, Tamil Nadu, India \\ *E-mail address: gmalakshmanan@gmail.com
}

\begin{abstract}
The genus Plectranthus belongs to the family Lamiaceae is found in wild and cultivated condition. In the present work, the cultivars of Plectranthus forskohlii have been collected from Tamil Nadu, Kerala and Karnataka at different places. The accessions collected from Karnataka showed high tuber size, length and volume when compared to accessions collected from Tamil Nadu and Kerala. The most significant observation was made in Karnataka and Tamil Nadu cultivar accessions which were grown in the same soil in field condition have much branched root tuber with significant fresh weight as compared with accessions from Kerala. The Kerala accessions were observed with less diffused root tuber with low fresh weight. On the basis of the present research, it was concluded that the phenotypic variations present in leaf, stem and root characters might be due to some genetic heritable variation which may exist in the accessions collected from different locality, and this require further study with respect to their genotypic nature of Plectranthus forskohlii.
\end{abstract}

Keywords: Plectranthus; Species; Phenotype; Genotype

\section{INTRODUCTION}

Plectranthus forskohlii (Willd) Briq. (Syn. C. forskohlii) that belongs to the family Lamiaceae, commonly known as Coleus, Pashanbedi (Sanskrit), Patharchur (Hindi), Manganiperu (Kannada), Marunthu koorkan (Tamil) which is grown throughout the country. Its tuberous roots are found to be a rich source of forskolin (Coleonol) used as a potential drug for hypertension, obesity, bronchitis, asthma, respiratory disorders, painful urination, insomnia and psoriasis (Ammon et al, 1982). Clinical studies on forskolin also indicates that it may have therapeutic benefit in angina and prevention of cancer metastases (Ammon et al, 1985).

Plectranthus forskohlii (Willd) Briq is considered to be originated from the Himalaya of Kumaon in Nepal, Bihar and Deccan peninsular of south India as well as Srilanka, Apparently, it has been also distributed in Egypt, Arabia, Ethiopia, Tropical East Africa and Brazil. In India, the plant is found on dry, barren hills at an altitude of about $2400 \mathrm{~m}$ with moderate rainfall of $400-500 \mathrm{~mm}$ and a mean annual temperature of $18-27^{\circ} \mathrm{C}$. The crop is being commercially grown in large area in Madhya Pradesh, Maharashtra, Kerala, Karnataka and Tamil Nadu. 


\title{
1. 1. Taxonomic status
}

P. forskohlii (Willd) Briq. is a member of mint family Lamiaceae. It is indigenous to India, and is recorded in Ayurvedic "Materia Medica" under the Sanskrit name "Makandi" and "Mayani" (Shah 1996). Taxonomic position of P. forskohlii (C. forskohlii) is as follows

\author{
Kingdom: Plantae \\ Class: Dicotyledones \\ Subclass: Gamopetalae \\ Series: Bicarpellatae \\ Order: Lamiales \\ Family: Lamiaceae \\ Genus: Plectranthus \\ Species: forskohlii. (Syn: C.forskohlii)
}

\section{2. Botanical description}

$P$. forskohlii is a perennial plant that grows to about $45-60 \mathrm{~cm}$ tall and aromatic in nature. It has four angled branched stems and nodes are often hairy. Leaves are 7.5 to $12.5 \mathrm{~cm}$ in length and 3 to $5 \mathrm{~cm}$ in width, usually pubescent, narrowed into petioles. Inflorescence is raceme, $15-30 \mathrm{~cm}$ in length; flowers are stout, 2 to $2.5 \mathrm{~cm}$ in size, usually perfect and calyx hairy inside. Upper lip of calyx is broadly ovate. The blue or lilac corolla is bilabiate. Lower lobes are elongated and concave so that they enclose the essential organs. The ovary is four parted and stigma two lobed and the flower is cross-pollinated by wind or insects (Bailey et al, 1942) The roots are tuberous, thick, fibrous, brown in colour, orange-red within and strongly aromatic. $P$. forskohlii is the only species of this genus to have fasciculated tuberous roots. The leaves and tubers have quite different odours. However, the growth habit of $P$. forskohlii is strikingly variable being erect, procumbent or decumbent. Similarly, the root morphology in different populations are also fascinatingly diverse, being tuberous, semi tuberous or fibrous (Non tuberous).

\section{MATERIALS AND METHODS}

The present study was conducted in different places of three states viz., Tamil Nadu, Kerala and Karnataka. The total fourteen genotypes were collected and the information was recorded on the field note book. The species are identified by using the Flora of the Presidency of Madras (J S Gamble 1935), Flora of Tamil Nadu (A. N. Henry and N. C. Nair) and Flora of Tamil Nadu Carnatic (Matthew 1983).

\section{1. Herborization}

All the species cited as medicinal plants were collected from the field at reproductive stage, with the help of informants in duplicate. A field sheet was recorded with collectors name, vernacular name, local name and ecological parameters. The herbarium samples were dried, processed, identified taxonomically and the names were confirmed with the help of standard flora. 


\section{RESULT AND DISCUSSION}

\section{1. Morphometric analysis of different accessions of Plectranthus forskohlii}

\section{1. 1. Plant height}

The accession PF 14 record the minimum plant height mean value of 32.85 and it differed significantly with other accessions. The accession PF 3 recorded the highest plant height (mean value of $56.96 \mathrm{~cm}$ ) and the other accessions PF 1, PF 10, PF11 were recorded more than $50 \mathrm{~cm}$ mean value of plant height.

\section{1. 2. Number of Branches}

The highest number of branches with mean value of 116.79 was recorded in PF 11 accession. The least number of branches with mean value of 37.94 was recorded in PF 2. Out of 14 accessions, 8 accessions were recorded with more than 100 numbers of branches per plant mean value.

\subsubsection{Number of Leaves:}

The data pertaining to the mean value of number of leaves per plant was recorded highest in PF 1. The least mean value of number of leaves was recorded in PF 7. There are 7 accessions with mean value of number of leaves more than 300 per plant was recorded.

\section{1. 4. Internodal Length}

There were significant differences among different accessions of Plectranthus forskohlii with reference to the internodal length were observed. The accession PF 11 and PF4 showed highest mean value of internodal length when compared to other accessions recorded.

\section{1. 5. Stem Diameter}

The accession PF3 recorded with highest mean value for stem diameter 2.47 compared with other accessions. The least stem diameter mean value was observed in PF 8 accession. No significant difference in the mean value of stem diameter in PF 9 and PF 11 was recorded.

\section{2. Number of tubers}

The number of tubers per plant in different accessions of Plectranthus forskholii showed significant differences among different accessions. The accession PF 12 recorded the significantly highest number of tubers per plant mean value (29.44). The least number of mean value of tubers per plant was recorded in the accession PF2 (18.15) which were closer with mean value of tuber per plant in the accession PF 5 (19.97).

\section{2. 1. Length of tubers}

The mean value of length of tubers per plant was given in the table showed that the highest mean value of length of tuber per plant was recorded in the accession PF 4 (15.44). The least length of mean value of tuber was observed in the accession PF 13 (9.36). There was no significant difference in the mean of value of length of tubers in the accessions PF 6 , PF 7, and PF 8. 


\section{2. 2. Diameter of tubers}

The highest mean value of diameter of tuber was observed in the accession PF 8 (1.78) and the lowest mean value recorded in the accession PF 6 (1.35). The least significant difference in the mean value of diameter of tuber was observed in PF1, PF2, PF10 and Pf13.

\section{2. 3. Fresh weight of tubers}

The fresh weight of tubers of 14 accessions was recorded in the Table 4. The highest mean value of fresh weight of tuber was recorded in the accession PF 4 (534.75). The PF2 accession recorded with lowest mean value of fresh weight of tuber and it was 252.45. There are five accessions were observed with more than $300 \mathrm{gm}$ mean value of fresh weight of tuber per plant.

\section{2. 4. Volume and Density of tubers}

The volume and density of tubers were calculated values. The PF6 accession recorded the highest mean value for volume of tuber when compared with other accessions. Whereas the density of tubers of the accession PF 10 and PF 14 were recorded with the same mean value for volume of tubers (1.30).

\section{3. Extraction and estimation of Forskolin content in selected Plectranthus forskohlii accessions}

Forskolin content in the root was determined by high performance thin layer chromatography. Standard forskolin and other samples were spotted on precoated silica plates as narrow bands under nitrogen atmosphere. A mixture of benzene and ethyl acetate was used as the mobile phase. The plates were sprayed with anisaldehyde sulphuric acid reagent and heated at $110{ }^{\circ} \mathrm{C}$ for $5 \mathrm{~min}$. Orange fluorescence observed at $366 \mathrm{~nm}$ was optically detected and quantified at $315 \mathrm{~nm}$ using TLC scanner for quantification of the separated compounds in the chromatogram. Forskolin content per plant was obtained by multiplying dry weight of the root by its forskolin concentration.

In the present study total fourteen accessions were collected from various palces within the three states mentioned. The genotypes are named by PF1, PF2, PF3 to PF14. The PF1, PF2, PF3, PF4 and PF5 were collected from Pollachi, Coimbatore, Sirupakkam, Chinnasalem and Avatti of the States of Tamil Nadu respectively. In Kerala, three species were collected from, Palode, Kunnamagalam and Manjeri namely PF6, PF7 and PF8. The genotypes PF9, PF10, PF11, PF12, PF13 and PF14 are collected in the palces of Mysore, Mandya, Hunsur, Yelahanga, Dharwad and Doddabathi of Karnataka state respectively (Table 1).

The collected accessions from Karnataka state showed significant morphological variations with respect to size, shape of the root tuber and habit form of stem when compared with accessions collected from Tamil Nadu and Kerala. The five accessions collected from Tamil Nadu namely PF1, PF2, PF3, PF4 and PF5 exhibited leaf variations in size and shape, presence or absence of hairs on the stem when compared to Kerala accessions. The wild accessions collected from Kerala showed non-tuber form and the roots are fasciculate in nature. 
Table 1. Collection sites of Plectranthus forskohlii accessions in Tamil Nadu, Kerala and Karnataka.

\begin{tabular}{|c|c|c|c|}
\hline S. No. & Accession name & LOCATIONS & STATE \\
\hline 1 & PF1 & Pollachi & Tamil Nadu \\
\hline 2 & PF2 & Coimbatore & Tamil Nadu \\
\hline 3 & PF3 & Sirupakkam & Tamil Nadu \\
\hline 4 & PF4 & Chinnasalem & Tamil Nadu \\
\hline 5 & PF5 & Avatti & Tamil Nadu \\
\hline 6 & PF6 & Palode & Kerala \\
\hline 7 & PF7 & Kunnamangalam & Kerala \\
\hline 8 & PF8 & Manjeri & Kerala \\
\hline 9 & PF9 & Mysore & Karnataka \\
\hline 10 & PF10 & Mandya & Karnataka \\
\hline 11 & PF11 & Hunsur & Karnataka \\
\hline 12 & PF12 & Yelahanga & Karnataka \\
\hline 13 & PF13 & Dharwad & Karnataka \\
\hline 14 & PF14 & Doddabathi & Karnataka \\
\hline
\end{tabular}

Table 2. Morphometrical analysis of different accessions of Plectranthus forskholii (Mean values calculated from pooled data on 150 days after transplanting).

\begin{tabular}{|c|c|c|c|c|c|c|}
\hline S. No. & $\begin{array}{c}\text { Accession } \\
\text { Name }\end{array}$ & $\begin{array}{c}\text { Plant } \\
\text { height } \\
\text { (cm) }\end{array}$ & $\begin{array}{c}\text { Number of } \\
\text { Branches } \\
\text { per plant }\end{array}$ & $\begin{array}{c}\text { Number } \\
\text { of Leaves } \\
\text { per plant }\end{array}$ & $\begin{array}{c}\text { Internodal } \\
\text { Length } \\
\text { (cm) }\end{array}$ & $\begin{array}{c}\text { Stem } \\
\text { Diameter } \\
\text { (cm) }\end{array}$ \\
\hline 1 & PF 1 & 54.49 & 109.37 & 349.29 & 1.12 & 2.40 \\
\hline 2 & PF 2 & 45.77 & 37.94 & 273.79 & 1.05 & 2.21 \\
\hline 3 & PF 3 & 56.96 & 104.07 & 339.12 & 1.20 & 2.47 \\
\hline 4 & PF 4 & 30.52 & 111.05 & 301.99 & 1.24 & 2.30 \\
\hline 5 & PF 5 & 50.94 & 100.44 & 315.94 & 1.15 & 2.41 \\
\hline 6 & PF 6 & 45.67 & 94.66 & 284.25 & 1.10 & 2.24 \\
\hline 7 & PF 7 & 46.23 & 101.34 & 267.65 & 1.09 & 2.21 \\
\hline 8 & PF 8 & 49.58 & 108.64 & 298.66 & 1.11 & 1.98 \\
\hline 9 & PF 9 & 50.64 & 110.87 & 315.92 & 1.16 & 2.34 \\
\hline 10 & PF 10 & 52.28 & 115.45 & 336.48 & 1.21 & 2.16 \\
\hline
\end{tabular}




\begin{tabular}{|l|c|c|c|c|c|c|}
\hline 11 & PF 11 & 53.92 & 116.79 & 308.63 & 1.29 & 2.34 \\
\hline 12 & PF 12 & 48.03 & 105.91 & 298.64 & 1.04 & 2.19 \\
\hline 13 & PF 13 & 47.66 & 103.44 & 320.41 & 1.06 & 2.31 \\
\hline 14 & PF 14 & 32.85 & 95.39 & 269.58 & 1.01 & 2.36 \\
\hline
\end{tabular}

Table 3. Morphometric analysis of tubers of different accessions of Plectranthus forskohlii (Mean values calculated from pooled data on 150 days after transplanting).

\begin{tabular}{|c|c|c|c|c|c|c|c|}
\hline S. No. & $\begin{array}{c}\text { Accession } \\
\text { Name }\end{array}$ & $\begin{array}{c}\text { Number } \\
\text { of tubers } \\
\text { per plant }\end{array}$ & $\begin{array}{c}\text { Length } \\
\text { of tubers } \\
\text { per } \\
\text { plant } \\
\text { (cm) }\end{array}$ & $\begin{array}{c}\text { Diameter } \\
\text { of tubers } \\
\text { per plant } \\
\text { (cm) }\end{array}$ & $\begin{array}{c}\text { Fresh } \\
\text { weight } \\
\text { of tubers } \\
\text { per } \\
\text { plant } \\
\text { (gm) }\end{array}$ & $\begin{array}{c}\text { Volume } \\
\text { of tubers } \\
\text { per plant } \\
\text { (cc) }\end{array}$ & $\begin{array}{c}\text { Density } \\
\text { of tubers } \\
\text { per } \\
\text { plant } \\
\text { (g/cc) }\end{array}$ \\
\hline 1 & PF 1 & 21.36 & 14.17 & 1.63 & 288.89 & 225.08 & 1.29 \\
\hline 2 & PF 2 & 18.15 & 12.41 & 1.60 & 252.45 & 230.79 & 1.10 \\
\hline 3 & PF 3 & 23.95 & 13.96 & 1.46 & 314.79 & 262.80 & 1.20 \\
\hline 4 & PF 4 & 41.37 & 15.44 & 1.68 & 534.75 & 487.04 & 1.10 \\
\hline 5 & PF 5 & 19.97 & 10.66 & 1.52 & 275.49 & 251.53 & 1.10 \\
\hline 6 & PF 6 & 22.74 & 11.84 & 1.35 & 284.73 & 219.26 & 1.30 \\
\hline 7 & PF 7 & 21.64 & 11.66 & 1.48 & 269.47 & 214.65 & 1.11 \\
\hline 8 & PF 8 & 26.35 & 13.48 & 1.78 & 398.33 & 236.54 & 1.20 \\
\hline 9 & PF 9 & 24.35 & 14.69 & 1.39 & 288.36 & 224.98 & 1.15 \\
\hline 10 & PF 10 & 25.33 & 13.57 & 1.65 & 386.33 & 242.31 & 1.30 \\
\hline 11 & PF 11 & 27.13 & 11.33 & 1.59 & 412.36 & 249.62 & 1.20 \\
\hline 12 & PF 12 & 29.44 & 10.49 & 1.44 & 397.64 & 241.33 & 1.20 \\
\hline 13 & PF 13 & 21.34 & 9.36 & 1.63 & 299.03 & 239.85 & 1.10 \\
\hline 14 & PF 14 & 25.78 & 14.33 & 1.59 & 346.25 & 229.33 & 1.30 \\
\hline
\end{tabular}

Table 4. Estimation of forskolin content in the root tubers of Plectranthus forskohlii accessions.

\begin{tabular}{|c|c|c|c|}
\hline S. No. & Accession Name & $\begin{array}{c}\text { Forskolin } \\
\text { concentration ( \% ) }\end{array}$ & $\begin{array}{c}\text { Forskolin content } \\
\text { mg/plant }\end{array}$ \\
\hline 1 & PF 1 & 0.57 & 45.6 \\
\hline 2 & PF 2 & 0.74 & 74.58 \\
\hline 3 & PF 3 & 0.75 & 112.50 \\
\hline
\end{tabular}




\begin{tabular}{|c|c|c|c|}
\hline 4 & PF 4 & 0.93 & 75.51 \\
\hline 5 & PF 5 & 0.83 & 80.89 \\
\hline 6 & PF 6 & 0.79 & 85.13 \\
\hline 7 & PF 7 & 0.86 & 68.62 \\
\hline 8 & PF 8 & 0.73 & 72.19 \\
\hline 9 & PF 9 & 0.76 & 73.45 \\
\hline 10 & PF 10 & 0.77 & 89.41 \\
\hline 11 & PF 11 & 0.88 & 98.43 \\
\hline 12 & PF 12 & 0.92 & 79.66 \\
\hline 13 & PF 13 & 0.72 & 72.36 \\
\hline 14 & PF 14 & 0.76 & 76.22 \\
\hline
\end{tabular}

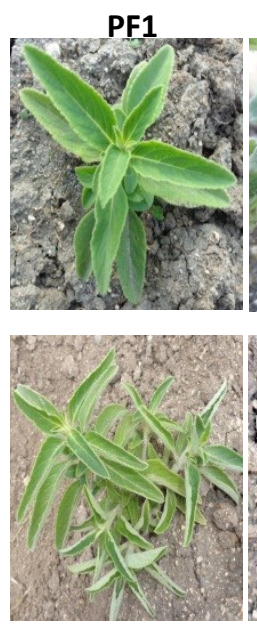

PF8
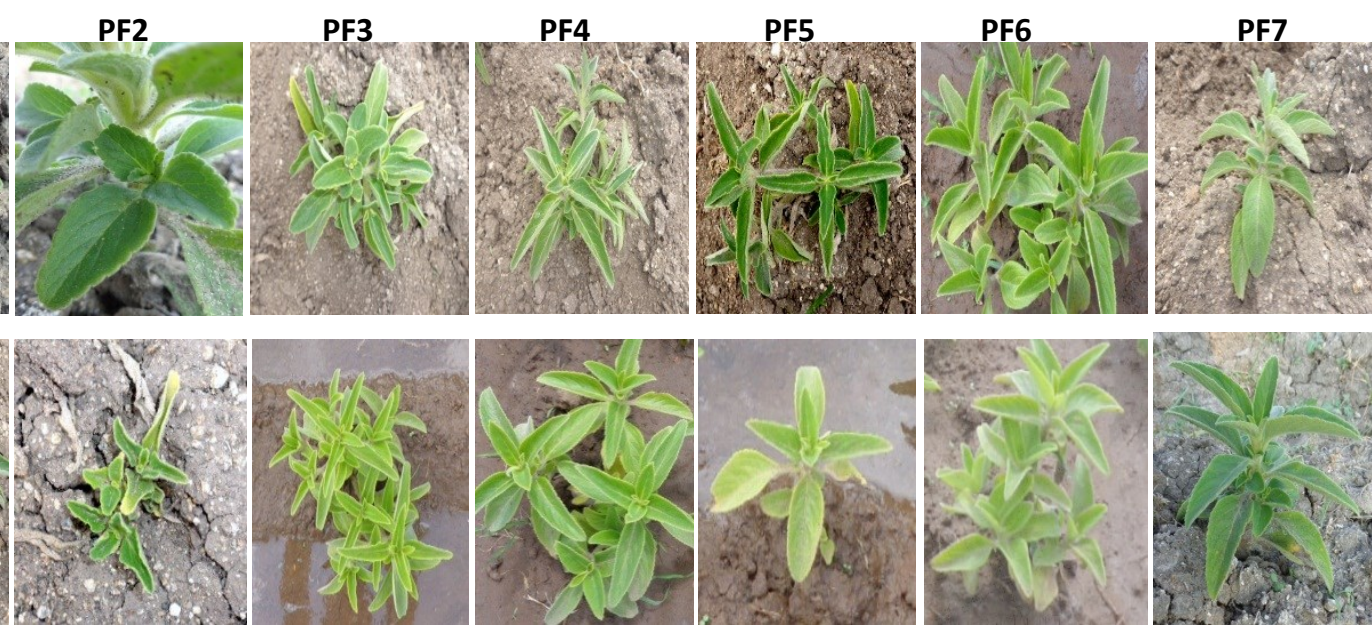

PF9

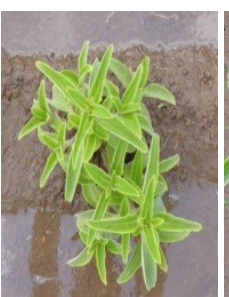

PF10

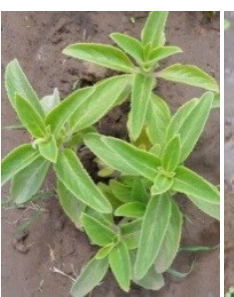

PF11

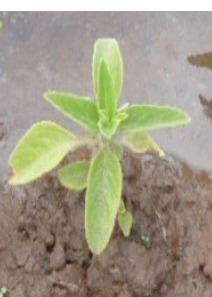

PF12

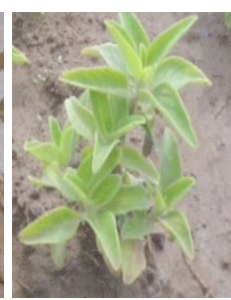

PF13

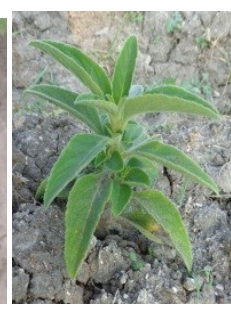

PF14

Figure 1. Morphology of Plectranthus forskohlii accessions in Tamil Nadu, Kerala and Karnataka.

\section{CONCLUSION}

The objectives of the study were to assess the nature and extent of diversity within collected accessions based on key morphological characters such as leaf, stem and useful part (Root) of $P$. forskohlii. The results showed that the characters have large contribution to the variability. In all the three states studied, large pool of $P$. forskohlii germplasm is formed in farmer's field and forest areas. Nevertheless this germplasm is being lost especially in wild condition, because of its large demand, human interference such as deforestation and replace this plant in farmer's field by high value crops. Therefore, there is a need to characterize, conserve and maintain the germplasm to serve as source of desired genotypes for further breeding purposes and to reduce further genetic erosion. Therefore, this study helps in 
preliminary screening, evaluation and selection of best accessions based on the above morphological characters which is suitable to characterize the high yield accessions as well as future germplasm improvement of $P$. forskohlii.

\section{Acknowledgement}

The authors are grateful to the University Grant Commission, Govt. of India, New Delhi for providing the financial Support.

\section{References}

[1] Ammon H.P., Kemper F.H., Med. Welt. 33 (1982) 148-153.

[2] Ammon H.P., Muller A.B., Planta. Med. 6 (1985) 473-477.

[3] Bailey LH. (1942). Standard Cyclopedia of Horticulture, Macmillan, New York.

[4] Gamble J S \& Fischer C E C. (1959). The flora of the Presidency of Madras, Reprinted Edition, Vol. I-III, (Botanical Survey of India, Calcutta).

[5] Henry A.N., Kumari G.R., Chitra V. (1987). Flora of Tamil Nadu, India, Series I, Vol. II \& III, (Botanical Survey of India, Southern Circle, Coimbatore).

[6] Nair N.C., Henry A.N. (1983). Flora of Tamil Nadu, India, Series I, Vol I, (Botanical Survey of India, Southern Circle, Coimbatore).

[7] Mathew K.M. (1983). An excursion flora of Tamil Nadu, India, (Oxford and IBH Publishing Co. Ltd., New Delhi).

[8] C. Kavitha, E. Vadivel, K. Rajamani, Res. J. Med. Plant. 3(2) (2009) 75-79.

[9] L. J. Valdes, S. G. Mislankar, A. G. Paul., Economic botany 41(4) (1987) 474-483. 